\title{
Thioctic Acid and Vitamin B Complex Improves Clinical Sings in Diabetic Peripheral Neuropathy
}

\author{
ANDREEA ROTARU ${ }^{1}$, CARMEN VALERIA ALBU ${ }^{2}$, DIANA RODICA TUDORASCU ${ }^{3}$, BOGDAN CATALIN ${ }^{1}$, MIHAELA GHEONEA*, \\ ION UDRISTOIU ${ }^{5}$, MARIA IANCAU ${ }^{1}$ \\ 'University of Medicine and Pharmacy of Craiova, Physiology Department, 2 Petru Rares Str., 200349 Craiova, Romania \\ ZUniversity of Medicine and Pharmacy of Craiova, Neurology Department, 2 Petru Rares Str., 200349 Craiova, Romania \\ 3University of Medicine and Pharmacy of Craiova, Internal Medicine Department, 2 Petru Rares Str., 200349 Craiova, Romania \\ 4University of Medicine and Pharmacy of Craiova, Neonatology Department, 2 Petru Rares Str., 200349 Craiova, Romania \\ EUniversity of Medicine and Pharmacy of Craiova, Psychiatry Department, 2 Petru Rares Str., 200349 Craiova, Romania
}

\begin{abstract}
Diabetic neuropathy is the most common cause of neuropathy worldwide and it is estimated to affectabout half of people with diabetes. The goal of our study is to compare the effectiveness of thioctic acid treatment alone versus the efficacy of thioctic acid plus vitamin B complex in patients with diabetic peripheral polyneuropathy (DPN). We conducted a prospective, observational study staring from October 2017 to December 2018, in which we included 56 DPN patients. Depending on the Michigan neuropathic screening instrument (MNSI) we divided the patients into two subgroups: patients with MNSI <7 and patients whose MNSI did not decrease sufficiently during the therapeutic protocol. 36 patients (64.2\%) of the total patients enrolled in the study had an MNSI <7 at one of the follow-up meetings. These patients were also divided according to the therapeutic protocol applied in a group of patients who were treated with only thioctic acid (TA group) and in a group of patients who were treated with thioctic acid plus vitamin $B$ complex (TA $+B$ group). We noticed a greater proportion of patients who had a MNSI $<7$ in the TA $+B$ group. This study revealed that the treatment of peripheral diabetic neuropathy with thioctic acid plus Vitamin $B$ complex compared to thioctic acid alone was superior in terms of improving clinical features.
\end{abstract}

Keywords: diabetes mellitus, thioctic acid, Vitamin B complex, diabetic peripheral neuropathy

In the common clinical practice, diabetes mellitus is among the most common causes of polyneuropathy, diabetic neuropathy affects almost half of the diabetic patients [1,2]. It should be noted that diabetic neuropathy is characterized by a progressive and slow destruction of the nerve fibers and it can affect both the somatic nervous system and the vegetative nervous system [3]. If the signs of diabetic neuropathy are early recognized and a proper management of this disease is established, patients with diabetes may present reduced morbidity and mortality, especially in terms of cardiovascular disease, the risk of painless lesions in the legs may be reduced and, in general, by applying certain symptomatic treatments the quality of the patients' lives can be increased [3].

The majority of the diabetic neuropathy syndromes most likely result from ischemia or infarction of the nerve or nerve fascicles due to diabetic microvasculopathy [2].

The International Diabetes Federation (IDF) identified a 425 million global diabetes prevalence worldwide in 2017, predicting 628 million people for 2045 [4,5]. Increasing prevalence of diabetes in general population across the globe will also be accompanied by an increased number of complications of this particular disease [23]. Diabetic neuropathy is the most common cause of neuropathy worldwide and it is estimated to affect about half of the people with diabetes [5-7].

\section{Experimental part}

The aim of the study

The purpose of our study is to compare the effectiveness of the treatment with thioctic acid alone versus the effectiveness of the treatment with thioctic acid and the vitamin $B$ complex in patients with diabetic peripheral polyneuropathy (DPN).
Materials and methods

We conducted a prospective observational study starting from October 2017 to December 2018 in which we included 56 patients consecutively to avoid bias.

The inclusion criteria in the study were the presence of diabetes, diagnosed according to the American Diabetes Association criteria [8-10], the diagnosis of peripheral diabetic neuropathy sustained by both the clinical examination performed by a senior neurologist and the assessment of nerve conduction, the patients' acceptance to participate in the study and to be present in the followup, and nevertheless the glycemic profile controlled by the diabetologist for at least 3 months prior to inclusion in our study. Exclusion criteria were the refusal of the patients to take part in the study, etiology of peripheral neuropathy other than diabetes ( paraneoplastic diseases, autoimmune diseases, severe hypothyroidism, renal dysfunction, excessive alcohol consumption, immunosuppressive medication, etc.), pregnancy or the presence of grade III obesity or morbid obesity.

At the time they were included in the study, all patients were evaluated according to a standard protocol that consisted of anamnesis, clinical examination, resting electrocardiogram, common and specific blood tests (depending on the admission symptoms). Each patientwas enrolled in a database and for each patient a unique code was generated in order to avoid patient identification.

Each patient who presented the inclusion criteria in the study was randomly assigned to one of the two study groups. Thus, a group of patients (TA) received the first 10 days of once a day an intravenous dose of $600 \mathrm{mg}$ of thioctic acid (Thiossen, Solupharm Pharmazeutische Erzeugnisse $\mathrm{GmbH}$ Industrienstrasse 3, Melsungen Germany) then a maintenance dose of one tablet of $600 \mathrm{mg}$ once a day for the next 12 weeks (Thiossen, Artesan Pharma, Luchow,

\footnotetext{
* email: drmgheonea@yahoo.com; Phone: +40723613835
} 
Germany). The second group received both thioctic acid (according to the therapeutic protocol described above) plus vitamin $B$ complex $(T A+B)$, initially in the first 10 days, once a day an intravenous dose (slow intravenous administration) of thiaminoclorohydrin (B1 $100 \mathrm{mg}$ ), pyridoxinehydrocloride (B6 $100 \mathrm{mg}$ ) and cyanocobalamin (B12 1000 ig) (MILGAMMA N, Worwag Pharma, Boblingen, Germany) then twice a day capsules of Vitamin B complex (40 mg of thiaminoclorohydrochloride-B1, $90 \mathrm{mg}$ of pyridoxinohydrochloride B6) and cyancobalamin-B12 250 ig, MILGAMMA N, Worwag Pharma, Boblingen, Germany).

After initial evaluation, on inclusion in the study, patients were then evaluated at 10 days (after finishing the injectable treatment) and then at a 4-week interval for a period of at least 16 weeks.

Initially and also at every subsequent follow-up, in order to evaluate the response to the therapeutic protocol used in peripheral diabetic neuropathy, we utilized the Michigan neuropathy screening instrument (MNSI) [11-14]. The MNSI calculation consists of both patient involvement by completing a questionnaire with 15 questions (the questionnaire was translated into Romanian) as well as clinical examination usually performed by the neurologist or diabetologist, as described in the studies published until present [11-18]. An MNSI $\geq 7$ value was considered pathological [13].

All patients included in our study were informed about the study and signed both the informed and the acceptance consent in order to be enrolled in the study. The study was approved by the Ethics Committee of the University of Medicine and Pharmacy of Craiova and was carried out according to all the provisions of the national and international fora for conducting medical studies, mentioning here Good Clinical Practice, the Helsinki Declaration issued by the International Medical Association (WMA - world medical association) and all relevant regulations.

After all data was gathered, statistical tests were performed using GraphPad Software (version 6, GraphPad Software, La J olla, CA, USA). All results were recorded as mean and standard deviation. In order to compare the average of two groups, we used the t-student test, while to compare the averages of more than two groups, we used ANOVA variant analysis. To evaluate the effectiveness of the two therapeutic methods, we used the Kaplan-Meier evolution curves with the Log-rank (Mantel-Cox) test. To quantify the importance of the link between a variable (that characterized a particular study group) and evolution time, we used the hazard rate (HR) with the associated confidence interval. In all cases, the statistically significant difference was recorded if the value of $P$ was less than 0.05 .

\section{Results and discussions}

In our study, we prospectively included 56 patients diagnosed with peripheral diabetic neuropathy (DPN). 23 patients were enrolled in the TA group (patients who were treated with thioctic acid only after the therapeutic protocol described above) and 23 patients were enrolled in the TA $+B$ group (patients treated with thioctic acid plus with Vitamin B complex after the therapeutic protocol described above). The TA group included patients with an average age of $59.31 \pm 8.56$ years, 9 of which were women (39\%) and 14 were men (61\%). TA + B group included patients with an average age of $61.18 \pm 9.32$ years, represented by 12 women (52\%) and 11 males (48\%). Clinical-pathological features from baseline of recruited patients are shown in Table 1.

Depending on the Michigan neuropathic screening instrument (MNSI) we divided the patients into two other subgroups: patients who obtained MNSI $<7$ during the therapeutic protocol and patients where MNSI did not decrease sufficiently enough along the therapeutic protocol. Thus, we observed that at the end of the 16-week follow-up, 36 patients $(64.2 \%)$ of the total patients enrolled in the study had a MNSI $<7$ in one of the in follow-up meetings. These patients were also divided according to the therapeutic protocol applied in a group of patients who were treated with only thioctic acid (TA group) and in a group of patients who were treated with thioctic acid plus vitamin B complex (TA + B group). We noticed that 10 days after the onset of treatment in the TA group, there was no patient who had MNSI $<7(0 \%)$, while in the TA + B group, only one patient had MNSI $<7(0.5555573 \%)$. At 4

\begin{tabular}{|c|c|c|c|}
\hline $\begin{array}{l}\text { Clinical-pathological features from baseline } \\
\text { of recruited patients }\end{array}$ & $\begin{array}{l}\text { TA }(n=23,50 \\
\%)\end{array}$ & $\begin{array}{l}\mathrm{TA}+\mathrm{B}(\mathrm{n}=23, \\
50 \%)\end{array}$ & P value \\
\hline Age (years) & $59.31 \pm 8.56$ & $61.18 \pm 9.32$ & $0.380^{F}$ \\
\hline Gender & & & $0.040^{8}$ \\
\hline Male & $14(61 \%)$ & $11(48 \%)$ & \\
\hline Female & $9(39 \%)$ & $12(52 \%)$ & \\
\hline Type 1 diabetes & $7(30 \%)$ & $9(39 \%)$ & $0.150^{8}$ \\
\hline Type 2 diabetes & $16(70 \%)$ & $14(61 \%)$ & $0.340^{8}$ \\
\hline Diabetes duration (years) & $12.6 \pm 3.1$ & $12.1 \pm 2.9$ & $0.344^{*}$ \\
\hline $\mathrm{HbA1C}(\%)$ & $7.3 \pm 1.3$ & $7.6 \pm 1.5$ & $0.570^{=}$ \\
\hline Insulin treatment (\%) & $14(\%)$ & $16(\%)$ & $0.235^{8}$ \\
\hline Neuropathy duration (years) & $3.2 \pm 2.4$ & $3.5 \pm 2.6$ & $0.655^{*}$ \\
\hline MNSI & $10.1 \pm 3.2$ & $10.8 \pm 3.4$ & $0.635^{*}$ \\
\hline Nephropathy (\%) & $3(13 \%)$ & $5(22 \%)$ & $0.322^{8}$ \\
\hline Retinopathy (\%) & $18(78 \%)$ & $17(74 \%)$ & $0.610^{8}$ \\
\hline Body mas index $\left(\mathrm{kg} / \mathrm{m}^{2}\right)$ & $29.7 \pm 7.2$ & $29.3 \pm 6.7$ & $0.940^{=}$ \\
\hline Active smokers & $15(65 \%)$ & $18(78 \%)$ & $0.424^{8}$ \\
\hline Dyslipidemia & $16(70 \%)$ & $19(83 \%)$ & $0.390^{8}$ \\
\hline Cardiovascular disease & & & $0.150^{8}$ \\
\hline Yes & $7(30 \%)$ & $9(39 \%)$ & \\
\hline No & $16(70 \%)$ & $14(61 \%)$ & \\
\hline Systolic blood pressure (mmHg) & $126.045 \pm 14.183$ & $132.143 \pm 15.544$ & $0.145^{\#}$ \\
\hline Mean blood pressure $(\mathrm{mmHg})$ & $95.833 \pm 8.676$ & $92.760 \pm 9.230$ & $0.650^{\mp}$ \\
\hline Diastolic blood pressure (mmHg) & $80.727 \pm 7.780$ & $78.835 \pm 7.762$ & $0.123^{\#}$ \\
\hline \multicolumn{4}{|c|}{$\begin{array}{l}\text { TA }=\text { Thioctic Acid } T A+B=\text { Thioctic acid }+ \text { Vitamin } B \text { complex. MNSI } \text { Michigan neuropathy } \\
\text { screening instrument. The data are reported as mean } \pm S D \text { for contimuous variables and as absolute } \\
\text { number and percentage value } \% \text { for qualitative variables. \#t test. } * \text { Chi-square test }\end{array}$} \\
\hline
\end{tabular}

Table 1

CLINICAL-PATHOLOGICAL FEATURES FROM BASELINE OF RECRUITED PATIENTS 
weeks follow-up in the TA group, one patienthad MNSI $<7$ $(0.6944428 \%)$, while in the TA + B group two patients had MNSI $<7(1.936729 \%)$. At 8 weeks follow-up in the TA group two patients had MNSI $<7(3.452934 \%)$ while in the TA + B group 6 patients had MNSI $<7(7.384689 \%)$. At 12 weeks follow-up in the TA group 3 patients had MNSI $<7$ (7.475723\%), while in the TA + B group 7 patients had MNSI <7 (16.38895\%). At 16 weeks follow-up in the TA group 5 patients had MNSI $<7(20.32632 \%)$ while in the TA + B group 8 patients had MNSI <7 (34.96919\%). By performing the LogRank test, we obtained a $P$ value of 0.0362 with a Hazard Ratio for TA group of $0.4813(95 \% \mathrm{Cl}$ of ratio 0.2428 to 0.9541 ) and a Hazard Ratio for TA + B group of $2.078(95 \% \mathrm{Cl}$ of ratio 1.048 to 4.119$)$. This is also highlighted in Figure 1.

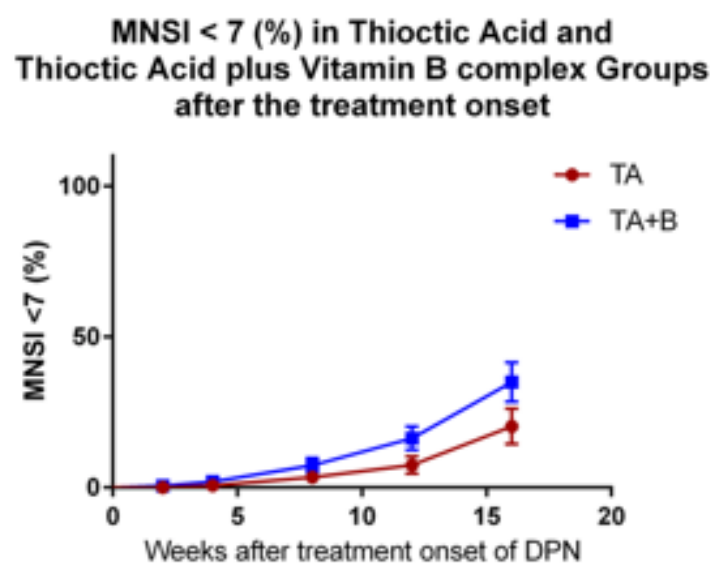

Fig. 1. Michigan neuropathic screening instrument (MNSI) $<7$ in thioctic acid and thioctic acid and Vitamin B complex groups after the treatment onset.

Also, at the end of the therapeutic and follow-up period, we observed a decrease in tension values for all patients included in the study. Thus, for systolic blood pressure (sBP) there was a decrease from $126.0455 \pm 14.18311 \mathrm{mmHg}$ to $117.1875 \pm 7.498682 \mathrm{mmHg}(P=0.0035)$ at the end of the treatment, for mean blood pressure (mBP) there was a decrease from $95.83334 \pm 8.676951 \mathrm{mmHg}$ to 84.39584 \pm 5.494171 at the end of treatment $(P=0.01)$ and for diastolic blood pressure (dBP) there was a decrease from $80.72727 \pm 7.780009 \mathrm{mmHg}$ to $68.000 \pm 5.372221 \mathrm{mmHg}$ $(P=0.002)$. This is highlighted in Figure 2.

Blood pressure at the onset and after the treatment

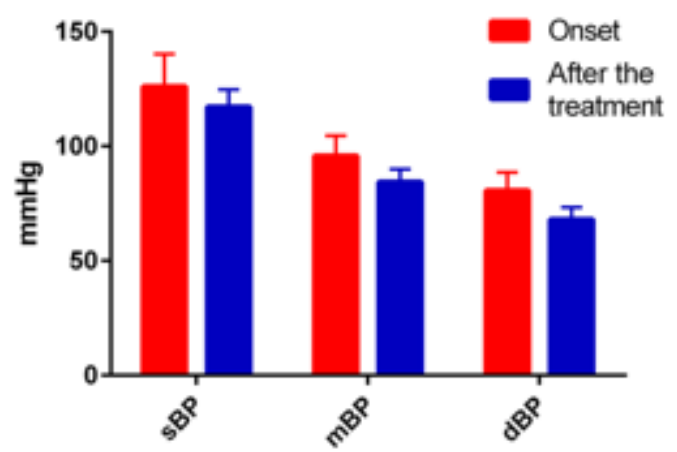

Fig. 2. Blood pressure at onset and after the treatment

Diabetic peripheral neuropathy continues to remain a major public health problem [1, 15-21].

In the DCCT / EDIC (Diabetes Control and Complications Trial / Epidemiology of Diabetes Interventions and Complications) study, it has been shown that good glycemic control in patients with type 1 diabetes only lags and does not prevent the development of peripheral diabetic neuropathy $[22,23]$.

In this study we looked at the effectiveness of the treatment with thioctic acid alone and also combined with Vitamin B complex for the peripheral diabetic neuropathy, using the Michigan neuropathy screening tool (MNSI).

Thioctic acid or alpha lipoic acid has so far been very studied in the treatment of peripheral diabetic neuropathy, since it acts as an agent that reduces oxidative stress, thus decreasing vascular dysfunction [24]. The efficacy of this oxidative stress-relieving agenthas been studied in several clinical trials, such as NATHAN 1 trial or others [21-23]. In the NATHAN 1 trial, the effectiveness of thioctic acid was assessed in patients with mild moderate impairment of DPN for 4 years. It was found that most patients responded positively to treatment compared to placebo, thus from a clinical point of view, while from the nerve conduction point of view no statistically significant differences were observed [24-28].

On the other hand, vitamin B complex plays an important role in the treatment of diabetic neuropathy in many ways. Thus, it has been found that Vitamin B complex can reduce high levels of homocysteine in the blood (levels associated with the degree of diabetic neuropathy), but it also plays an essential role in repairing and regeneration of peripheral tissues [29-33].

\section{Conclusions}

This study revealed the superiority of the treatment of peripheral diabetic neuropathy with thioctic acid plus Vitamin B complex compared to thioctic acid alone, in terms of improving clinical features. Due to the small number of patients included in our study, further randomized clinical trials are required to confirm our observations.

\section{References}

1.IQBAL, Z., AZMI, S., YADAV, R., FERDOUSI, M., KUMAR, M., CUTHBERTSON, D.J., LIM, J., MALIK, R.A., ALAM, U., Diabetic Peripheral Neuropathy: Epidemiology, Diagnosis, and Pharmacotherapy, Clin Ther, 40, 6, 2018, p. 828849

2.DEWANJ EE, S., DAS, S., DAS, A.K., BHATTACHARJEE, N., DIHINGIA, A., DUA, T.K., KALITA, J., MANNA, P., Molecular mechanism of diabetic neuropathy and its pharmacotherapeutic targets, Eur J Pharmacol, 833, 2018, p. 472-523.

3.BOULTON, A.J.M., VILEIKYTE, L., Painful Diabetic Neuropathy in Clinical Practice. Springer-Verlang London Limited, 2011, p. 1-81.

4.*** International Diabetes Federation. IDF Diabetes Atlas. 8th edn. Brussels, Belgium: International Diabetes Federation; 2017.

5.THIBAULT, V., BELANGER, M., LEBLANC, E., BABIN, L., HALPINE, S., GREENE, B., MANCUSO, M., Factors that could explain the increasing prevalence of type 2 diabetes among adults in a Canadian province: a critical review and analysis, Diabetol Metab Syndr, 8, 2016, p. 71. 6.YOUNG, M.J ., BOULTON, A.J., MACLEOD, A.F., WILLIAMS, D.R., SONKSEN, P.H., A multicentre study of the prevalence of diabetic peripheral neuropathy in the United Kingdom hospital clinic population, Diabetologia, 6, 2,1993, p. 150-154.

7.BOULTON, A.J.M., GRIES, F.A., J ERVELL, J.A., Guidlines for the diagnosis and outpatient management of diabetic peripheral neuropathy, Diabet Med, 15, 1998, p. 508-514.

8.ALBERS, J.W., POP-BUSUI, R., Diabetic neuropathy: mechanisms, emerging treatments, and subtypes, Curr Neurol Neurosci Rep, 14, 2014, p. 473.

9.SINGER, C.E., COSOVEANU, C.S., CIOBANU, M.O., STOICA, G.A., PUIU, I., GRUIA, C.L., STREBA, L., CONSTANTIN, C., NEAGOE, C.D. Hirschprung's disease in different settings - a series of three cases from a tertiary referral center. Rom J Morphol Embryol, 56, 3, 2015, p. 1195-2000. 
10.MARINAU, L.D., SINGER, C.E., MESINA, C., NICULESCU, E.C., PUIU, I., PETRESCU, I.O., GEORMÃNEANU, C., ENCULESCU, A.C., TACHE, D.E., PURCARU, S.O., RÃCIULÃ, S., DAMIAN, C.L. Two girl patients with medulloblastoma. Case reports. Rom J Morphol Embryol, 58, 3, 2017, p. 1103-1108

11.FELDMAN, E..L, STEVENS, M.J., THOMAS, P.K., BROWN, M.B., CANAL, N., GREENE, D.A., A practical two-step quantitative clinical and electrophysiological assessment for the diagnosis and staging of diabetic neuropathy, Diabetes Care, 17, 11, 1994, p. 1281-1289.

12.MOGHTADERI, A., BAKHSHIPOUR, A., RASHIDI, H., Validation of Michigan neuropathy screening instrument for diabetic peripheral neuropathy, Clin Neurol Neurosurg, 108, 5, 2006, p. 477-481.

13.HERMAN, W.H., POP-BUSUI, R., BRAFFETT, B.H., MARTIN, C.L., CLEARY, P.A., ALBERS, J.W., FELDMAN, E.L., DCCT/EDIC Research Group, Use of the Michigan Neuropathy Screening Instrument as a measure of distal symmetrical peripheral neuropathy in Type 1 diabetes: results from the Diabetes Control and Complications Trial/ Epidemiology of Diabetes Interventions and Complications, Diabet Med, 29, 7, 2012, p. 937-944.

14.FATEH, H.R., MADANI, S.P., HESHMAT, R., LARIJANI, B. Correlation of Michigan neuropathy screening instrument, United Kingdom screening test and electrodiagnosis for early detection of diabetic peripheral neuropathy, J Diabetes Metab Disord, 15, 2016, p. 8.

15.BERBECE, S., ILIESCU, D., ARDELEANU, V., NICOLAU, A., J ECAN, C.R. Rev. Chim. (Bucharest), 68, no. 7, 2017, p. 1438-1441

16.NECHITA, D., NECHITA, F., MOTORGA, R., A review of the influence the anxiety exerts on human life, Rom J Morphol Embryol, 59, 4, 2018, p. 1045-1051.

17.NECHITA, F., NECHITA, D., PIRLOG, M.C., ROGOVEANU, I., Stress in medical students, Rom J Morphol Embryol, 5, 3, 2014, p. 1263-1266. 18.BERCEANU, C., CIUREA, E.L., CIRSTOIU, M.M., BERCEANU, S., OFITERU, A.M., MEHEDINTU, C., BERBECE, S.I., CIORTEA, R., STEPAN, A.E., BALSEANU, A.T., Rev. Chim. (Bucharest), 69, no. 9, 2018, p. 2396-2401

19.NECHITA, F., PIRLOG, M.C., CHIRITA, A.L., Circadian malfunctions in depression - neurobiological and psychosocial approaches, Rom J Morphol Embryol, 56, 3, 2015, p. 949-955.

20.LUPU, V.V., IGNAT, A., PADURARU, G., CIUBARA, A., IONIUC, I., CIUBARA, A.B., GHEONEA, C., BURLEA, M., The Study of Effects Regarding Ingestion of Corrosive Substances in Children. Rev. Chim. (Bucharest), 67,no. 12, 2016, p. 2501-2503.
21.ANOAICA, P.G., AMZOIU, E., BOZZINI, F., AVERIS, L.M.E., BUBULICA, M.V., GHEONEA, C.A., Predictive and Invariant in silico Model for the Transmembrane Partition Coefficient in a Wide Series of Benzene Derivatives.,Rev. Chim.(Bucharest), 66, no. 3, 2015, p. 390-395.

22.BERCEANU, C., PAITICI, S., BERCEANU, S., BRATILA, E., OFITERU, A.M., MEHEDINTU, C., BERBECE, S.I., NAVOLAN, D., OBLEAGA, C.V., BALSEANU, A.T., Rev. Chim. (Bucharest), 69, no. 8, 2018, p. 2245-2250 23.MARTIN, C.L., ALBERS, J.W., POP-BUSUI, R., DCCT/EDIC Research Group. Neuropathy and related findings in the diabetes control and complications trial/epidemiology of diabetes interventions and complications study, Diabetes Care, 37, 1, 2014, p. 31-38.

24.ZIEGLER, D., LOW, P.A., FREEMAN, R., TRITSCHLER, H., VINIK, A.I., Predictors of improvement and progression of diabetic polyneuropathy following treatment with $\alpha$-lipoic acid for 4 years in the NATHAN 1 trial, J Diabetes Complications, 30, 2,2016, p. 350-356. 25.FILIP, I.C., BERBECE, S., RADUCU, L., FLORESCU, I.P., ARDELEANU, V., JECAN, C.R., Mat. Plast., 54, no. 3, 2017, p. 414-417

26.BOGHDADI, M.A., AFIFY, H.E., SABRI, N., MAKBOUL, K., ELMAZAR, M. Comparative Study of Vitamin B Complex Combined with Alpha Lipoic Acid versus Vitamin B Complex in Treatment of Diabetic Polyneuropathy in Type 2 Diabetic Patients, Clin Exp Pharmacol, 7, 4, 2017, p. 241.

27.BERBECE, S.I., CONDRATOVICI PLESEA, A., PAVEL, L.L., GRIGORE, A.C., Rev. Chim. (Bucharest), 68, no. 5, 2017, p. 1075-1076

28.PAPANAS, N., ZIEGLER, D., Efficacy of $\alpha$-lipoic acid in diabetic neuropathy. Expert Opin Pharmacother, 15, 18, 2014, p. 2721-2731.

29.ARDELEANU, V., BERBECE, S.I., FLORESCU, I.P., J ECAN, C.R., Mat. plast., 54, no. 1, 2017, p. 37-40

30.ANG, C.D., ALVIAR, M.J., DANS, A.L., BAUTISTA-VELEZ, G.G., VILLARUZ-SULIT, M.V., TAN, J.J., CO, H.U., BAUTISTA, M.R., ROXAS, A.A., Vitamin B for treating peripheral neuropathy, Cochrane Database Syst Rev, 3, 2008 , p. CD004573.

31.J ECAN, C.R., NICOLAU, A., FLORESCU, I.P., ARDELEANU, V., BERBECE, S., Mat.Plast., 54, no. 1, 2017, p. 88-90

32.CRICIOTOIU, O., STANCA, D.I., GLAVAN, D.G., MIREA, C.S., MITA, A., CALBOREAN, V.,GHEORMAN V., UDRISTOIU, I., DIJ MARESCU, A.L., DAVITOIU, D.V., GHEONEA, D.I., Rev. Chim. (Bucharest), 70, no. 4, 2019, p. 1403-1405.

33.GHEORMAN, V., DINESCU, V.C., CRICIOTOIU, O., STANCA, D., CALBOREAN, V., MITA, A., MISCOCI, A., DAVITOIU, D.V., BALEANU, V.D., NEDELCUTA, R.M., DINESCU, S.N., DIJ MARESCU, A.L., VOICULESCU, D.I., UDRISTOIU, I., Rev. Chim. (Bucharest), 70, no. 4, 2019, p. 1406-1410.

$\overline{\text { Manuscript received: } 10.07 .2019}$ 